\title{
TUMOR DISSEMINATION AFTER THORACOSCOPIC RESECTION FOR LUNG CANCER
}

\author{
J. Buhr, MD, M. Hürtgen, MD, C. Kelm, MD, and K. Schwemmle, MD, Giessen, Germany
}

Many peripheral nodules of the lung that cannot be determined to be benign by means of radiographic assessment require resection to rule out malignancy. The rapid evolution of minimally invasive surgical techniques is stimulating new technical and surgical innovations. Growing enthusiasm for these minimally invasive surgical procedures has led to an expanded role for thoracoscopic or video-assisted thoracic surgery for the solution of many intrathoracic surgical problems. Thoracoscopic surgery has expanded from a rarely used technique for the evaluation of benign diseases to an operative approach used in the treatement of lung cancer. At this writing, there have been reports of nearly 100 thoracoscopic or video-assisted resections in the treatment of lung cancer. ${ }^{1,2}$

In January 1990, we began to perform thoracoscopic operations in our Department for General and Thoracic Surgery in Giessen, Germany. Since January 1992, we have elected a thoracoscopic approach for some nodules of the lung because of our good experiences with thoracoscopic wedge resection for such benign diseases as pneumothorax.

Although the decrease in postoperative pain is obvious in the early period after operation, ${ }^{3}$ there remains concern about oncologic aspects of this approach. We therefore report on two cases of tumor dissemination after thoracoscopic resection for lung cancer.

In 63 cases, nodules were resected by thoracoscopic wedge resection. In 21 cases, malignancy was demonstrated (14 metastases and seven primary lung cancers). In two of these patients, tumor cell dissemination was observed.

Case 1. In July 1992, we treated a patient who had bad lung function and a peripheral nodule $(1.5 \mathrm{~cm}$ diameter on computed tomographic scan) of the right upper lobe by means of thoracoscopic wedge resection. The histologic examination showed an adenocarcinoma without infiltration of the pleura visceralis (pathologic classification T1, grade 2). By means of intraoperative pleural lavage, we found tumor cells remaining after the thoracoscopic resection. In February 1994, we detected a metastatic nodule $(3 \mathrm{~cm}$ in diameter) at the site in the chest wall where the tumor was extracted during the thoracoscopic operation. On computed tomographic scan, we did not find any tumor recurrence in the lung. We performed a curative resection of the tumor located at the thoracic wall. One year after the operation, the patient was in good condition and remained free of any other tumor manifestations.

From the Department of General and Thoracic Surgery, Justus Liebig University, Giessen, Germany.

J Thorac Cardiovasc Surg 1995;110:855-6

Copyright $(1) 1995$ by Mosby-Year Book, Inc.

$0022-5223 / 95 \$ 5.00+0 \quad \mathbf{1 2 / 5 4 / 6 2 8 3 4}$
Case 2. A thoracoscopic wedge resection of a peripheral tumor $(2 \mathrm{~cm}$ diameter on computed tomographic scan) of a patient's right upper lobe was performed in January 1993. The histologic examination of the frozen section showed a close resection of an adenocarcinoma (only $3 \mathrm{~mm}$ distance between tumor and resection). We converted the operation to an open lobectomy and performed additional lymph node dissection. The histologic examination of the formalin-fixed tumor showed an adenocarcinoma with infiltration of the pleural visceralis. The final tumor stage was pathologic classification T2 N0, grade 2 . The result of pleural lavage cytologic examination was positive after the thoracoscopic resection. Pleural carcinosis, proved by histologic and cytologic examination, developed in this patient 6 months after the operation. The patient died 14 months after the operation.

Discussion. In our department, we perform thoracoscopic resection only for peripheral lung tumors smaller than $2 \mathrm{~cm}$ and in patients with compromised pulmonary reserves. All other patients were treated with open lung operations. In 46 cases, nodules of the lung were resected by thoracoscopic approach. If frozen sections indicated malignancy of the nodule, we converted to open lobectomy and performed formal lymph node dissection. Before and after thoracoscopic resection of the tumor, pleural lavage was performed for cytologic examination. This procedure should detect tumor cell spread before clinical manifestation. We also perform pleural lavage in open operations for lung cancer. ${ }^{4}$

These two case reports provide a warning for everyone who performs or tries to perform thoracoscopic operations for patients with from lung cancer. Thoracoscopic surgical methods are not able to adjust adequately to the specific growth pattern and paths of metastatic spread of lung cancer. The loss of palpation and the insufficiency of complete mediastinal lymph node dissection are responsible for the uncertain value of the new method for curative oncologic therapy. It is irresponsible to risk the internationally quite homogenous stage-related results currently obtained in the treatment of lung cancer for the sake of pursuing new technical methods. ${ }^{5,6}$ It is not our duty to create a new disease, such as tumor metastasis at the extraction site after thoracoscopic resection of lung cancer. Thoracoscopic resection for potentially malignant diseases should be restricted to superficial lesions smaller than $2 \mathrm{~cm}$. If the medical history or the thoracoscopic aspect suggests primary lung cancer, conversion to an open procedure is absolutely necessary.

\section{REFERENCES}

1. Kirby TJ, Mack, MJ, Landreneau RJ, Rice TW. Initial expierence with video-assisted thoracoscopic lobectomy. Ann Thorac Surg 1993;56:1248-53.

2. Landreneau RJ, Mack MJ, Hazelrigg SR, Dowling 
RD, Keenan RJ, Ferson PF. The role of thoracoscopy in the management of intrathoracic neoplastic processes. Semin Thorac Cardiovasc Surg 1993;5: 219-28.

3. Landreneau RJ, Mack MJ, Hazelrigg SR, et al. Prevalence of chronic pain after pulmonary resection by thoracotomy or video-assisted thoracic surgery. J THORaC Cardiovasc Surg 1994;107:1079-86.

4. Buhr J, Berghäuser $\mathrm{KH}$, Morr $\mathrm{H}$, Dobroschke J,
Ebner H. Tumor cells in intraoperative pleural lavage: an indicator for the poor prognosis in bronchogenic carcinoma. Cancer 1990;65:1801-4.

5. Linder A, Toomes H. Techniken der thorakoskopischen Chirurgie. Chirurg 1994;65:657-63.

6. Schirren J, Trainer S, Schneider P, Hendricks H, Müller KM, Vogt-Moykopf I. Sind videoassistierte thorakoskopische Resektionsverfahren in der onkologischen Chirurgie vertetbar? Chirurg 1994;65:664-70.

\section{TRANSVENTRICULAR MITRAL VALVE DILATOR: AN IMPROVED DESIGN CONCEPT}

Ajay Kaul, MCH, Susmit Bhattacharya, MS, Shirish Borker, MS, A. M. Patwardhan, MS, MS, A. P. Chaukar, MB, MS, and A. D. Abhyankar, MD, DM, Bombay, India

The concept of dilatation of stenotic valves was first put forward by Samways in 1898. The Tubbs Logan dilator (M/s All India Surgical Manufacturing Co., Bombay, India) came into use in the 1950 s to allow the surgeon to treat rheumatic mitral stenosis much more easily.

The advent of sophisticated catheterization laboratory techniques and the development of a percutaneous balloon mitral valve dilator minimized the surgical trauma of treatment of mitral stenosis. The balloon mitral valve dilator, whether of the Inoue (Toray Industries, Inc., Tokyo, Japan) or Mansfield type, is an adequate mitral valve dilator as shown by several authors. ${ }^{1-5}$ A study by Patel and associates ${ }^{6}$ concluded that the balloon was a superior dilator compared with the Tubbs dilator, whereas another study showed similar results with both. ${ }^{7}$

In our hospital percutaneous balloon mitral valvuloplasty and transventricular closed mitral valvotomy are performed regularly. We have observed that the gradients across the mitral valve fall to 3 to $5 \mathrm{~mm} \mathrm{Hg}$ after balloon dilatation but remain between 7 and $10 \mathrm{~mm} \mathrm{Hg}$ after a Tubbs dilatation. However, these values occurred in different sets of patients under different conditions and it was difficult to arrive at a conclusion regarding efficacy of each of the dilators.

We therefore wanted to do a comparative study in the same set of patients under the same conditions. We introduced the Inoue balloon dilator through the transventricular route and positioned the balloon across the mitral valve with a finger in the left atrium exactly as we do with the Tubbs dilator. Inflation was done by an assistant.

Twelve patients with mitral stenosis were chosen at random (Table I). The echocardiographic findings in

From L.T.M.M. College and L.T.M.G. Hospital, Sion, Bombay, India.

J THORAC CARDIOVASC SuRg 1995;110:856-9

Copyright (C) 1995 by Mosby-Year Book, Inc.

$0022-5223 / 95 \$ 5.00+0 \quad \mathbf{1 2 / 8 / 5 8 9 4 5}$
Table I. Data on 12 patients with mitral stenosis chosen for study

\begin{tabular}{ll}
\hline Men & 5 \\
Women & 7 \\
Age (yr) & $18-44$ \\
Mean age (yr) & 24 \\
Height (cm) & $130-177$ \\
Mean height (cm) & 162.4 \\
No. in NYHA class II & 4 \\
No. in NYHA class III & 8 \\
\hline
\end{tabular}

NYHA, New York Heart Association.

Table II. Echocardiographic evaluation

\begin{tabular}{ll}
\hline MVA $\left(\mathrm{cm}^{2}\right)$ & $0.6-1.3$ \\
$\begin{array}{l}\text { Gradient across mitral valve } \\
\text { (mm Hg) }\end{array}$ & $13-36$ \\
$\begin{array}{l}\text { Mean gradient across } \\
\text { mitral valve (mm Hg) }\end{array}$ & $21.43 \pm 7.87$ \\
$\begin{array}{l}\text { Pulmonary artery pressure } \\
\text { (mm Hg) }\end{array}$ & $35-75$ \\
Subvalvular status & $\begin{array}{c}\text { Moderate to severe } \\
\text { crowding }\end{array}$ \\
Calcification & $\begin{array}{c}\text { Nil in } 8 \text { patients; } \\
\text { minimal in 4 patients }\end{array}$ \\
Grade I mitral regurgitation & 2 patients \\
Atrial fibrillation & 1 patient; no LA clots \\
& on TEE \\
\hline
\end{tabular}

$M V A$, Mitral valve area; $L A$, left atrial.

these patients are summarized in Table II. They were divided into two groups. In group I $(n=5)$, valves were first dilated with a balloon introduced through the left ventricle. After complete dilatation we tried using a Tubbs dilator to see whether there were any changes. In group II $(n=7)$ the sequence was reversed. The maximum dilata- 